INFLAMMATORY BOWEL DISEASE

\title{
Epidemiology of appendicectomy in primary sclerosing cholangitis and ulcerative colitis: its influence on the clinical behaviour of these diseases
}

\author{
T H J Florin, N Pandeya, G L Radford-Smith
}

Gut 2004;53:973-979. doi: 10.1136/gut.2003.036483

Background and aims: Appendicectomy and smoking are environmental factors that are known to influence ulcerative colitis (UC). The phenotype of UC is different in patients with coexistent primary sclerosing cholangitis (PSC). This study investigates the interaction of appendicectomy and PSC on the epidemiology and clinical behaviour of colitis.

Methods: Patients were from the Brisbane IBD Research Group database. Controls were from the Australian twin registry. Seventy eight PSC-inflammatory bowel disease (PSC-IBD) patients, 12 pure PSC, and 294 UC patients were matched with 1466 controls by sex and birth cohort that comprised randomly selected twins from each twin pair. The effects of appendicectomy, smoking, or PSC on the onset of disease, disease extent, disease severity (as identified by immunosuppression-colectomy or liver transplant), and disease related complications (high grade dysplasia, colorectal cancer, or cholangiocarcinoma) were investigated using univariate and multiple logistic regression analyses.

Results: PSC-IBD patients had a more extensive colitis than UC patients $(p<0.0001)$ but required less immunosuppression $(p=0.007)$, which was independent of disease extent. They were more likely to have high grade dysplasia or colorectal cancer $(p=0.029)$ than UC patients. Appendicectomy rates in the PSC groups were not different from the control groups $(p=0.72,0.76)$, which was in sharp contrast with UC

See end of article for authors' affiliations

Correspondence to: AssociateProfessorTFlorin, UQ Department of Medicine, Mater Health Services' Adult Hospital, South Brisbane,

Queensland 4101, Australia;

t.florin@uq.edu.au

Accepted for publication 31 December 2003 where the rate was four times less $(p=0.0001)$. Prior appendicectomy appeared to be associated with an approximate five year delay in the onset of intestinal (PSC-IBD or UC) or hepatic (PSC) disease, which was independent of smoking. Appendicectomy did not independently alter the extent or severity of disease in PSC. In contrast, prior appendicectomy in UC was associated with more extensive disease but with a lesser requirement for immunosuppression or colectomy for the treatment of colitis $(p=0.004)$. There were trends for high grade dysplasia or colorectal cancer with appendicectomy in both PSC-IBD and UC. Although these trends were not statistically significant, colorectal cancer appeared more frequent with appendicectomy in a meta-analysis of the available UC data from this and another Australian study. Conclusions: In contradistinction to UC, appendicectomy did not significantly influence the prevalence of the PSC groups, or the extent of colitis in PSC-IBD, but as with UC, did appear to delay their onset. The extensive milder colitis, which is characteristic of PSC-IBD, relates to other poorly understood factors. Further prospective studies are required to determine any influence of appendicectomy on the extent of colitis in IBD and an associated dysplasia or colorectal cancer.

$\mathrm{T}$ here is a large body of evidence suggesting there is a low appendicectomy rate in patients with ulcerative colitis (UC). ${ }^{1-5}$ In addition, it has been reported by ourselves in a large sex and age matched case control study, ${ }^{6}$ and by others, ${ }^{78}$ that UC patients who have undergone prior appendicectomy develop a less severe colitis compared with those patients who have not undergone appendicectomy prior to the diagnosis of their UC. Our group also reported that, paradoxically, the colitis of UC patients with prior appendicectomy may be more extensive. Another study ${ }^{9}$ reported that ulcerative proctitis was more likely to evolve proximally in patients with prior appendicectomy.

There is also a substantial literature indicating that patients with primary sclerosing cholangitis (PSC) and inflammatory bowel disease (PSC-IBD) have, in general, a milder ${ }^{10-12}$ but more extensive colitis, ${ }^{13-16}$ which is often not a classical UC or Crohn's disease phenotype. ${ }^{12}{ }^{16}$ The more extensive colitis of PSC-IBD is associated with a higher incidence of dysplasia, dysplasia associated lesions and masses, and colorectal cancer, compared with those patients with classical UC. ${ }^{15-19}$ This may arise from the chronic inflammation of the underlying extensive colitis, which is often undertreated because it is clinically mild.
A number of questions are posed. Could appendicectomy be a common factor that influences both the development of the extensive colitis phenotype, and PSC, in PSC-IBD? In particular, is the appendicectomy rate prior to the onset of IBD greater in PSC-IBD than in UC controls? Could appendicectomy influence the clinically important complication of colorectal cancer in extensive colitis? What is the role of smoking in any of these potential associations?

\section{METHODS}

Participants

The PSC patient group

The PSC patient group in this study was ascertained from the Brisbane Inflammatory Bowel Disease Research Group and the Princess Alexandra Hospital Liver Transplant Service. The former has an extensive clinical database that is shared and maintained by two major IBD referral centres in Brisbanethe Royal Brisbane and Mater Hospitals. THJF and GLR-S from these IBD centres have practised uniform investigation

Abbreviations: PSC, primary sclerosing cholangitis; UC, ulcerative colitis; PSC-IBD, primary sclerosing cholangitis and inflammatory bowel disease; OR, odds ratio 
and treatment protocols since the inception of the database in 1995. The Brisbane IBD Research Group has close links with the Princess Alexandra Hospital Liver Transplant Service, with all patients with PSC-IBD also on the Brisbane IBD Research Group clinical database. The Liver Transplant Service is a tertiary referral centre for liver surgery in Queensland, northern New South Wales, and further afield. PSC patients comprised two groups: those with PSCIBD and those without IBD, denoted pure PSC. PSC was determined by ERCP or MRCP, and liver histology. The diagnosis of either UC or CD was based on standard clinical, radiological, and histological criteria, as defined by LennardJones. $^{20}$ Specific questions relating to appendicectomy, indication for surgery, and date of surgery were incorporated into the database. The date of appendicectomy was interrogated in relation to the date of diagnosis of IBD and birth date in order to investigate the temporal relationships between appendicectomy and onset of IBD or PSC, and age of appendicectomy and disease.

\section{The UC patient group}

This group comprised a consecutive series from the Brisbane IBD Research Group. It is the same UC cohort used in our previous study reported in $G u t^{6}$ with the exception that UC patients with PSC who were included in the UC patient group in that study are included in the PSC-IBD group in this study. In addition, patient disease related details were updated, including immunosuppression, colectomy, and the development of any disease related complications such as colorectal cancer. The database was described in our previous study ${ }^{6}$ but briefly, together with the history of all surgical episodes and their dates, the database records other phenotypic parameters including, inter alia: date of diagnosis, site and distribution of disease, IBD associated complications including PSC and colorectal cancer, disease activity (clinical, inflammatory indicators, endoscopic and pathological assessments), family history, detailed smoking history, medications, and contact details. Data were entered onto our database between 1995 and 2002. For the purpose of this study, disease distribution for UC patients was divided into two categories: those with disease always limited to the distal colon (up to the splenic flexure, which also included patients with ulcerative proctitis) and those with episodes of contiguous subtotal colitis (beyond the splenic flexure) or pancolitis. These assessments were based on colonoscopic and histological examination for all cases, and the maximum extent of disease attained by each patient during their history of UC was used as their disease distribution.

\section{The control group}

Controls were randomly selected from a twin database that contains 3808 twin pairs from around Australia enrolled with the Australian twin registry. During 1980-1982, these twin pairs took part in a health survey by mailed questionnaire which included items on common operations, including appendicectomy, and lifestyle habits, including smoking. ${ }^{21}$ One twin from each pair was selected randomly as a control, and five of these controls were matched by birth year and sex in five year birth intervals with each PSC-IBD case and with each pure PSC case. The ratio of UC controls to UC was less (3.5) because there were insufficient additional controls in the youngest birth cohorts to match five to one.

\section{Clinical parameters}

To compare smoking at diagnosis in patients and controls, smoking was recoded from categories of "never smoker, exsmoker, and current smoker" at diagnosis, to "never smoker or ever smoker" categories, because data were restricted to these two categories in our controls. The three categories of smoking were used without modification for comparison of smoking between patient groups. Appendicectomy was coded as yes or no at diagnosis of IBD if PSC-IBD or at diagnosis of PSC if pure PSC. Immunosuppression for IBD was defined as more than 12 months of continuous treatment with 6-mercaptopurine, azathioprine, methotrexate, or mycophenolate at the standard recommended doses, or at doses otherwise sufficient to cause leucopenia/lymphopenia. Histology of colectomy specimens was reviewed in patients who underwent this operation.

\section{Statistical methods}

Comparisons of categorical variables (such as smoking and appendicectomy prior to diagnosis) between patients and controls were conducted using Pearson's $\chi^{2}$ statistic or Fisher's exact test where cells had a count less than 5. Odds ratios (OR) together with $95 \%$ confidence intervals (CI) were calculated to estimate the relative risk of disease status associated with various exposures. Modelling with multiple logistic regression, with the corresponding calculation of adjusted two tailed p values, OR, and 95\% CI, was used to remove the effect of potential confounding where the model was clinically or biologically relevant or where univariate analysis $\mathrm{p}$ was less than or equal to 0.10 . Thus the modelling examined the effect of smoking and immunosuppression on disease/exposure associations and the effects of duration of disease or extent of the colitis on disease outcomes and associations. Comparisons of continuous normally distributed variables such as age at diagnosis and time between appendicectomy and diagnosis were made using $t$ tests and analysis of variance (ANOVA). All analyses were performed using SAS for Windows Release 8.2 (Cary, North Carolina, USA 2000).

\section{Ethics}

Ethics approval was obtained from the respective hospital research ethics committees and that of the Queensland Institute of Medical Research. Written informed consent was also obtained from patients for entry of data onto the databases.

\section{RESULTS}

\section{Patient and control characteristics (tables 1, 2)}

There were 90 cases of PSC ( 48 males, 42 females). Seventy eight $(87 \%)$ of the PSC patients had PSC-IBD. Sixty five were diagnosed as having UC, two indeterminate colitis, five Crohn's colitis, two Crohn's ileocolitis, and four Crohn's ileitis.

There were 294 UC cases (non-PSC patient controls)—152 males and 142 females. There were 1016 sex and birth cohort matched UC controls, 390 sex and birth cohort matched PSCIBD controls, and 60 sex and birth cohort matched pure PSC controls (table 1$)$. The patient and control groups were well matched for sex $(p>0.6)$ and age $(p=0.14$ for PSC-IBD and PSC-IBD controls, $>0.6$ for other patient and control groups).

Seventy of 71 (99\%) PSC colitis cases-not included were three other cases whose colonic site data were incomplete and the four cases of PSC-Crohn's ileitis - had an extensive colitis (table 2). These cases comprised 63 subtotal or total UC, five segmental non-contiguous but extensive Crohn's colitis, and two indeterminate total colitis. Only 13/76 PSCIBD ( $17 \%$, data missing for two) cases received immunosuppression for their IBD. Twenty five of 78 (32\%) PSC-IBD cases had undergone colectomy at the time of this review. We were able to verify the histology in 18 of these cases. Four colectomies (5\% of 78 ) were for colorectal cancer, three for high grade dysplasia (4\%), and 11 for treatment of IBD (14\%) which included four with longstanding quiescent disease and seven with inflammation (see tables 2,4). The seven 
Table 1 Characteristics of the patient and control groups

\begin{tabular}{|c|c|c|c|c|c|c|}
\hline Group & $\begin{array}{l}\text { PSC-IBD } \\
(n=78)\end{array}$ & $\begin{array}{l}\text { PSC-IBD controls } \\
(\mathrm{n}=390)\end{array}$ & $\begin{array}{l}\text { Pure PSC } \\
(n=12)\end{array}$ & $\begin{array}{l}\text { Pure PSC controls } \\
(n=60)\end{array}$ & $\begin{array}{l}\text { UC } \\
(n=294)\end{array}$ & $\begin{array}{l}\text { UC controls } \\
\text { ( } n=1016)\end{array}$ \\
\hline Age (y) (mean (SEM)) & $49.8(1.5)$ & $52.0(0.5)$ & $55.8(4.3)$ & $57.3(0.5)$ & $32.7(0.86)$ & $33.6(0.38)$ \\
\hline \multicolumn{7}{|l|}{ Sex } \\
\hline Female & 37 & 185 & 5 & 25 & 142 & 465 \\
\hline Male & 41 & 205 & 7 & 35 & 152 & 551 \\
\hline \multicolumn{7}{|l|}{ Smoking } \\
\hline Ever smoker & 23 & 188 & 7 & 29 & 136 & 482 \\
\hline Never smoker & $55^{*}$ & 202 & 5 & 31 & 158 & 534 \\
\hline \multicolumn{7}{|l|}{ Appendicectomy $\dagger$} \\
\hline No & 58 & 268 & 8 & 40 & 275 & 688 \\
\hline Yes & $19 \ddagger$ & 79 & $4 \S$ & 14 & 199 & 211 \\
\hline \multicolumn{7}{|l|}{ Age at appendicectomy } \\
\hline None & 58 & 268 & 9 & 40 & 275 & 688 \\
\hline$\leqslant 20 y$ & 11 & 50 & 1 & 9 & 8 & 136 \\
\hline$>20 y$ & 8 & 29 & 2 & 5 & 11 & 68 \\
\hline
\end{tabular}

PSC, primary sclerosing cholangitis; IBD, inflammatory bowel disease; UC, ulcerative colitis.

${ }^{*}$ Never smoking in PSC-IBD versus PSC-IBD controls, $\mathrm{p}=0.004$, odds ratio (OR) $=2.2$ (confidence interval (CI) 1.3-3.8).

†Appendicectomy data not available for one PSC-IBD, 43 PSC-IBD controls, six pure PSC controls, and 117 UC controls.

$\ddagger$ Appendicectomy in PSC-IBD versus UC, $p<0.0001, \mathrm{OR}=4.7(\mathrm{Cl} 2.4-9.5)$.

§Appendicectomy in pure PSC versus UC, $p=0.008, O R=7.2(C l 2.0-26)$.

-Appendicectomy in UC versus UC controls, $\mathrm{p}=0.0001, \mathrm{OR}=0.23(\mathrm{Cl} 0.14-0.37)$.

colectomy specimens with inflammation demonstrated mild to moderately severe colitis; none had severe active colitis.

Values shown in table 2 for disease extent and severity in PSC-IBD compare with extensive colitis in 121/293 UC cases $(41 \%$, one case of missing data in this field; $\mathrm{p}<0.0001$, $\mathrm{OR}=100(\mathrm{CI}$ 14-727)), immunosuppression in 76/294 UC cases $(26 \%, p=0.10)$, and colectomy in $71 / 294$ UC cases $(24 \%, p=0.14)$. Immunosuppression, when adjusted for extent of colitis, was significantly less likely in PSC-IBD compared with UC $(p=0.007, \quad$ OR $=0.36 \quad(0.17-0.77))$ although immunosuppression was independently associated with extensive colitis $(\mathrm{p}=0.009, \mathrm{OR}=2.0(1.2-3.4))$. Only four colectomies $(1.4 \%)$ in UC were for colorectal cancer and five $(1.7 \%)$ for high grade dysplasia, which was significantly less than in PSC-IBD ( $p=0.029$, OR $=3.6$ (CI 1.3-10.2)). All cancer/high grade dysplasia cases in our patient groups had extensive colitis. The OR values for immunosuppression or disease extent, or cancer related colectomy versus patient group were not significantly confounded by duration of disease.

\begin{tabular}{|c|c|c|c|}
\hline Clinical parameter & $\begin{array}{l}\text { PSC-IBD } \\
\text { (n (\%)) }\end{array}$ & $\begin{array}{l}\text { UC } \\
\text { (n (\%)) }\end{array}$ & $\begin{array}{l}\text { p Value } \\
\text { (OR (CI)) }\end{array}$ \\
\hline \multicolumn{4}{|l|}{ Extensive colitis* } \\
\hline No & 1 & 172 & $<0.0001$ \\
\hline Yes & $70(99)$ & $121(41)$ & $100(14-727)$ \\
\hline \multicolumn{4}{|l|}{ Immunosuppression } \\
\hline No & & 218 & $0.007 \dagger$ \\
\hline Yes & $13(17)$ & $76(26)$ & $0.36(0.17-0.77)$ \\
\hline \multicolumn{4}{|l|}{ Colectomy } \\
\hline No & 53 & 223 & 0.14 \\
\hline Yes & $25(32)$ & $71(24)$ & \\
\hline High grade dysplasia & 3 & 5 & \\
\hline Colon cancer & 4 & 4 & \\
\hline Total & $7(9)$ & $9(1.4)$ & $\begin{array}{l}0.029 \ddagger \\
3.6(1,3-10.2)\end{array}$ \\
\hline
\end{tabular}

PSC, primary sclerosing cholangitis; IBD, inflammatory bowel disease; UC, ulcerative colitis; OR, odds ratio; Cl, confidence interval. *Excluded from this row, four patients with pure ileal PSC and three patients with incomplete colonic site data.

tp adjusted for extensive colitis; $p=0.10$ for univariate analysis of immunosuppression versus patient group; $p=0.009$ for

immunosuppression and extensive colitis adjusted for patient group, $\mathrm{OR}=2.0(\mathrm{Cl} 1.2-3.4)$.

$\ddagger A l l 16$ cancer/high grade dysplasia patients had extensive disease $(p<0.0001)$.
Appendicectomy and disease behaviour PSC and appendicectomy

There were appendicectomy data for 89 (99\%) PSC patients. Mean age of patients at appendicectomy in our PSC-IBD group was 21.4 (SEM 1.6) years. Mean age at appendicectomy in our pure PSC patients was 21.0 (5.7) years.

The appendicectomy rate (table 1) in the PSC-IBD group was $24.7 \%$, which was not different from the appendicectomy rate in the age and sex matched control group $(23.2 \%$, $\mathrm{p}=0.76)$. The appendicectomy rate in pure PSC patients was $33 \%(\mathrm{p}=0.72)$. (The appendicectomy rate for all PSC $(25.8 \%)$ was not different from matching controls $(23.2 \%, \mathrm{p}=0.69))$.

Mean age at diagnosis of IBD (table 3 ) in PSC-IBD patients was 32.5 years for prior appendicectomy which was four years later than in the PSC-IBD without prior appendicectomy group $(p=0.098)$. Mean age at diagnosis of PSC in all PSC cases was 42.5 years for appendicectomy and six years earlier for no appendicectomy $(\mathrm{p}=0.06)$. Age at diagnosis of IBD or PSC versus appendicectomy was not confounded by smoking in a multivariate model.

Age at primary liver transplant also tended to be higher with appendicectomy (table 3). The primary liver transplant rate was $55 \%$ in the no appendicectomy group versus $48 \%$ in the appendicectomy group $(\mathrm{p}=0.75)$. Three patients—all in the no appendicectomy group-had undergone a second liver transplant operation.

The extent of colitis in PSC-IBD was not different in patients with appendicectomy (table 4).

Appendicectomy did not significantly alter other parameters of disease severity or complications in the PSC-IBD or pure PSC patient groups-parameters such as colectomy, immunosuppression, liver transplant, high grade dysplasia or colorectal cancer, and cholangiocarcinoma (table 4). Thus mild colitis in PSC-IBD, as identified by less requirement for immunosuppression or colectomy for colitis, was not associated with appendicectomy $(\mathrm{p}=0.38)$. While the colectomy rate for colorectal cancer or high grade dysplasia in patients with a prior appendicectomy $(16 \%)$ appeared to be more than twice the rate in patients who had not undergone appendicectomy prior to diagnosis (7\%), this was not statistically significant $(\mathrm{p}=0.35)$. This was not influenced by immunosuppression or smoking in a multivariate model.

\section{UC and appendicectomy (table 5)}

In UC, extensive colitis was $58 \%$ with appendicectomy but $40 \%$ without appendicectomy $(p=0.13)$. On the other hand, 
Table 3 Age at diagnosis of IBD or PSC or, at time of first liver transplant versus appendicetomy

\begin{tabular}{|c|c|c|c|}
\hline \multirow[b]{2}{*}{ Patient group (n) } & \multicolumn{2}{|c|}{$\begin{array}{l}\text { Age at diagnosis (y) } \\
\text { (mean (SEM)) }\end{array}$} & \multirow{2}{*}{$\begin{array}{l}\text { Appendicectomy } \\
\text { age ( } p \text { value) }\end{array}$} \\
\hline & App + & App- & \\
\hline PSC-IBD (78*) & $32.5(0.37)$ & $28.2(0.26)$ & 0.10 \\
\hline Pure PSC (12) & $48.6(9.7)$ & $40.9(6.2)$ & 0.54 \\
\hline All PSC (90*) & $42.5(0.49)$ & $36.8(0.23)$ & 0.06 \\
\hline Liver transplant (47) & $45.1(0.77)$ & $42.9(0.42)$ & 0.55 \\
\hline UC (294) & $37.9(3.07)$ & $32.4(0.89)$ & 0.12 \\
\hline
\end{tabular}

PSC, primary sclerosing cholangitis; IBD, inflammatory bowel disease; UC, ulcerative colitis.

$\mathrm{App}+$, prior appendicectomy; App-, no appendicectomy prior to diagnosis.

*Appendicectomy data missing in one PSC-IBD patient.

immunosuppression was 5.6\% with appendicectomy and $27 \%$ without appendicectomy $(\mathrm{p}=0.05, \mathrm{OR}=0.13$ (CI 0.02-0.99)) but extensive disease was independently associated with an increased risk of immunosuppression in UC $(p=0.008$, $\mathrm{OR}=2.1 \quad(1.2-3.5))$. Thus UC with prior appendicectomy was associated with a milder disease as defined by the lesser requirement for immunosuppression or colectomy for severe colitis $(\mathrm{p}=0.004, \mathrm{OR}=0.09$ (CI 0.01-0.72)).

High grade dysplasia or colorectal cancer was $11 \%$ with appendicectomy and $2.5 \%$ without appendicectomy $(\mathrm{p}=$ 0.11 ). This was not confounded by disease extent because all the high grade dysplasia and colorectal cancer patients had extensive disease (subtotal or total colitis), and it was not due to a higher rate of colectomy in the appendicectomy group (table 5). Nor was high grade dysplasia or colorectal cancer influenced by immunosuppression $(p=0.99)$ in a multivariate model with appendicectomy. Smoking did not influence these relationships in a multivariate logistic model.

Six UC patients had an appendicectomy at a mean duration of 8.8 (range 2-29) years after diagnosis of their IBD. None in this small cohort developed a liver biochemical abnormality to prompt investigation for PSC or autoimmune hepatitis over a subsequent follow up of a mean of $4.0(0.2-19)$ years.

\section{Smoking in PSC, UC, and controls}

PSC and smoking

PSC patients (12 pure PSC and 78 PSC-IBD cases) were mainly never smokers (versus ever smokers) at diagnosis, with $67 \%$ never smokers compared with $52 \%$ never smokers of 450 controls $(p=0.011)$. This relationship with never smoking at diagnosis was stronger for PSC-IBD $(p=0.004)$. Never smoking was $42 \%$ in pure PSC $(\mathrm{p}=0.75)$ (table 1 ).

Current, never, or ex-smoking in PSC did not correlate with age at diagnosis of PSC $(p=0.58)$ in a multivariate model. Nor did smoking correlate with immunosuppression (ANOVA, $\mathrm{p}=1.0$ ) or colectomy in the 78 PSC-IBD cases $(p=0.80)$. Mean age at diagnosis of IBD in PSC-IBD was 31.5 years in ex-smokers, 29.5 years in never smokers, and 16.0 years in current smokers $(\mathrm{p}=0.08)$.

\section{UC and smoking}

UC patients (294 cases) were not different from 1016 UC controls with respect to never smoking, with 54\% and 53\% never smokers, respectively $(\mathrm{p}=0.72)$ (table 1$)$. They were more likely to be ex-smokers at diagnosis, with $43 \%$ exsmokers, compared with all PSC with $26 \%$ ex-smokers $(p=0.003, O R=2.3($ CI $1.3-3.9))$. Mean age at diagnosis of UC was 37.7 years in ex-smokers, 29.2 years in never smokers, and 24.4 years in current smokers $(p<0.0001)$.

\begin{tabular}{|c|c|c|c|}
\hline Clinical parameter & $\begin{array}{l}\text { App+ } \\
\text { (n (\%)) }\end{array}$ & $\begin{array}{l}\text { App- } \\
\text { (n (\%)) }\end{array}$ & $\mathrm{p}$ Value \\
\hline \multicolumn{4}{|l|}{ PSC-IBD } \\
\hline \multicolumn{4}{|l|}{ Liver transplant } \\
\hline No & 10 & 26 & 0.60 \\
\hline Yes & $9(47)$ & $32(55)$ & \\
\hline CholangioCa & 0 & 3 & 1.0 \\
\hline \multicolumn{4}{|l|}{ Extensive colitis } \\
\hline No & 0 & 1 & 0.54 \\
\hline Yes & $19(100)$ & $51(98)$ & \\
\hline \multicolumn{4}{|l|}{ Immunosuppression } \\
\hline No & 16 & & 0.86 \\
\hline Yes & $3(16)$ & $10(17)$ & \\
\hline \multicolumn{4}{|c|}{ Immunosuppression or colectomy for colitis* } \\
\hline No & 14 & 33 & 0.38 \\
\hline Yes & $4(29)$ & $19(36)$ & \\
\hline \multicolumn{4}{|l|}{ All colectomy } \\
\hline No & 13 & 39 & 0.92 \\
\hline Yes & $6(32)$ & $19(33)$ & \\
\hline High grade dysplasia & 2 & 1 & \\
\hline Colorectal cancer & 1 & 3 & \\
\hline Total & $3(16)$ & 4 (7) & 0.35 \\
\hline \multicolumn{4}{|l|}{ Pure PSC } \\
\hline \multicolumn{4}{|l|}{ Liver transplant } \\
\hline No & 2 & 4 & 1.0 \\
\hline Yes & $2(50)$ & $4(50)$ & \\
\hline CholangioCa & 0 & 0 & \\
\hline \multicolumn{4}{|l|}{ All PSC } \\
\hline \multicolumn{4}{|l|}{ Liver transplant } \\
\hline No & 12 & 30 & 0.75 \\
\hline Yes & $11(48)$ & $36(55)$ & \\
\hline CholangioCa & $0(0)$ & $3(5)$ & 0.57 \\
\hline \multicolumn{4}{|c|}{$\begin{array}{l}\text { App+, prior appendicectomy; App-, no appendicectomy prior to diagnosis. } \\
\text { PSC, primary sclerosing cholangitis; IBD, inflammatory bowel disease; CholangioCa, cholangiocarcinoma. } \\
\text { *Seven colectomy cases for which histological verification was not possible were excluded. There were } 11 \text { (of 18) } \\
\text { colectomy cases for treatment of colitis, none of which demonstrated severe colitis. }\end{array}$} \\
\hline
\end{tabular}


Table 5 Clinical behaviour in ulcerative colitis patients by prior appendicectomy

\begin{tabular}{|c|c|c|c|c|}
\hline Clinical parameter & $\begin{array}{l}\text { App+ } \\
\text { (n (\%)) }\end{array}$ & $\begin{array}{l}\text { App- } \\
\text { (n (\%)) }\end{array}$ & $\mathrm{p}$ Value & OR $(95 \% \mathrm{Cl})$ \\
\hline \multicolumn{5}{|l|}{ Extensive colitis } \\
\hline No & & 164 & \multirow[t]{2}{*}{0.13} & \\
\hline Yes & $11(58)$ & $110(40)$ & & \\
\hline \multicolumn{5}{|l|}{ Immunosuppression } \\
\hline No & & 201 & \multirow[t]{2}{*}{$0.049^{*}$} & \multirow{2}{*}{$\begin{array}{l}0.13 \dagger \\
(0.02-0.99)\end{array}$} \\
\hline Yes & $1(5.6)$ & $74(27)$ & & \\
\hline \multicolumn{5}{|c|}{ Colectomy for severe disease } \\
\hline No & & 201 & \multirow[t]{2}{*}{0.08} & \multirow{2}{*}{$\begin{array}{l}5.3 \\
(0.69-41)\end{array}$} \\
\hline Yes & $1(5.9)$ & $67(25)$ & & \\
\hline \multicolumn{5}{|c|}{$\begin{array}{l}\text { Immunosuppression or colectomy for severe } \\
\text { disease }\end{array}$} \\
\hline No & & 161 & \multirow[t]{2}{*}{0.004} & \multirow{2}{*}{$\begin{array}{l}0.09 \\
(0.01-0.72)\end{array}$} \\
\hline Yes & $1(5.9)$ & $107(40)$ & & \\
\hline \multicolumn{5}{|l|}{ All colectomy } \\
\hline No & 16 & 207 & \multirow{2}{*}{\multicolumn{2}{|c|}{0.58}} \\
\hline Yes & $3(16)$ & $68(25)$ & & \\
\hline \multicolumn{5}{|l|}{ Colectomy for: } \\
\hline High grade dysplasia & 0 & 5 & & \\
\hline Colorectal cancer & 2 & 2 & \multirow{2}{*}{\multicolumn{2}{|c|}{0.11}} \\
\hline Total & $2(11)$ & $7(2.5)$ & & \\
\hline \multicolumn{5}{|c|}{$\begin{array}{l}\text { App+, prior appendicectomy; App-, no appendicectomy prior to diagnosis. } \\
\text { * } \mathrm{p} \text { value adjusted for disease extent, multivariate analysis. } \\
\text { †Multivariate analysis (odds ratio (OR); confidence interval }(\mathrm{CI}) \text { ). } \\
\text { Immunosuppression versus appendicectomy, univariate } O R=0.15(\mathrm{Cl} 0.02-1.15), p=0.052 \text {. Immunosuppression } \\
\text { correlated independently with disease extent, } p=0.008, O R=2.1(\mathrm{Cl} 1.2-3.5) \text {. }\end{array}$} \\
\hline
\end{tabular}

Current, never, or ex-smoking did not correlate in univariate analyses with disease extent, dysplasia/colorectal cancer, colectomy, or immunosuppression in 294 UC cases, or in a multivariate model.

\section{DISCUSSION}

This study compared appendicectomy and smoking in PSCIBD, pure-PSC, UC, and controls matched for sex and birth cohort. The results are in agreement with other studies that found never smoking to correlate with PSC but not with UC. ${ }^{62}$ UC, on the other hand, correlates strongly with exsmoking at diagnosis in this and other studies. ${ }^{22-24}$ This study also investigated the effect of appendicectomy on disease behaviour. Other investigators have not looked at this in such detail. The study confirms the well known inverse association between appendicectomy and UC with an $\mathrm{OR}=0.23$ (CI 0.14-0.37) in this study, which was independent of smoking. Also confirmed in this study were the associations ${ }^{13-16}$ between PSC-IBD and extensive colitis $(\mathrm{p}<0.0001)$, and PSC-IBD with high grade dysplasia/colorectal cancer, with an $\mathrm{OR}=3.6$ (CI 1.3-10.2) compared with UC. That all patients with high grade dysplasia/colorectal cancer in this study had extensive colitis is consistent with the suspicion that the association is in large part due to more extensive colitis in PSC-IBD. ${ }^{15}$ PSC-IBD patients also tended to have a milder colitis, which has been reported elsewhere. ${ }^{10}{ }^{11}$ Thus PSC-IBD patients required less immunosuppression, which was independent of the extent of colitis $(p=0.007)$.

A major finding of this study was that appendicectomy prior to diagnosis was not different between PSC (PSC-IBD or pure PSC) and the large group of appropriately matched controls. This is in sharp contrast with the situation in UC. Nor did we discover PSC developing in our six UC patients who had an appendicectomy prior to diagnosis of their colitis, although the small number and short duration of follow up after appendicectomy (mean $4.0(0.2-19)$ years) is not long enough to draw conclusions.

We are aware of three other studies that reported on appendicectomy, PSC, and UC (table 6). None discovered a difference in PSC and controls versus appendicectomy. Furthermore, a meta-analysis of these and the present studies, while affirming the widely reported inverse relation between
UC and appendicectomy, showed no difference in the appendicectomy rate of PSC and controls (table 6).

However, although there was no difference between PSC and control groups versus appendicectomy, there was a consistent trend for age at diagnosis of PSC-IBD or PSC to be delayed by four to six years in patients who had prior appendicectomy (table 3). Age at diagnosis of UC in UC cases was also delayed by appendicectomy (table $3, p=0.12$ ). ${ }^{6} 725$ Furthermore, UC patients with prior appendicectomy have clinically milder disease $\mathrm{e}^{6-8}$ based on their reduced requirement for immunosuppression or colectomy for severe colitis $(p=0.004, \mathrm{OR}=0.09)$, which we first reported in 2002, ${ }^{6}$ even though extent of colitis may be greater in UC patients who have undergone appendicectomy $(p=0.13)$. On the other hand (see table 4), colitis extent and most other parameters of severity in PSC (need for immunosuppression, colectomy, liver transplant, cholangiocarcinoma) were not influenced by appendicectomy. An exception was high grade dysplasia/ colorectal cancer in PSC-IBD which was twice as frequent with appendicectomy but this was not statistically significant $(\mathrm{p}=0.35)$.

High grade dysplasia/colorectal cancer in the UC group also appeared to be more frequent with prior appendicectomy but again this relationship was not statistically significant (table $5, \mathrm{p}=0.11$ ). The trend was not due to immunosuppression therapy. This is consistent with other data in the IBD literature which demonstrate that immunosuppression does not influence the development of colorectal cancer. ${ }^{26}$ However, the association with high grade dysplasia/colorectal cancer was statistically significant when the data from the 294 UC and 78 PSC-IBD cases of this study were combined (Fisher's exact test, $\mathrm{p}=0.039$ ). Furthermore, the association between appendicectomy and colorectal cancer attained statistical significance $(p=0.004$, table 6) when our Brisbane data were combined with the Sydney ${ }^{25}$ data. (Dysplasia data were not available for the Sydney cohort and so the Brisbane high grade dysplasia data were not used in the meta-analysis in table 6).

The odds ratio for colorectal cancer in patients with prior appendicectomy from these combined datasets was 15 times the risk in patients who had not undergone this operation prior to diagnosis of their IBD. The meta-analyses are 
Table 6 Meta-analyses of studies that have investigated appendicectomy in UC or PSC

\begin{tabular}{|c|c|c|c|c|}
\hline \multicolumn{5}{|c|}{ I: Appendicectomy rate in patient and control groups: meta-analysis of four studies } \\
\hline Study & PSC (n) & $U C(n)$ & Control group (n) & Comments \\
\hline (a) van Erpecum ${ }^{40}$ & 59 & 130 & 197 & $\begin{array}{l}\text { Small groups, reported all } \\
\text { appendicectomy-before and after } \\
\text { diagnosis. }\end{array}$ \\
\hline (b) Mitchell ${ }^{41}$ & 170 & 170 & 170 & Did not find low App+ in UC. \\
\hline (c) Selby ${ }^{25}$ & 23 & 236 & 280 & Small PSC group. \\
\hline (d) Florin & 90 & 294 & 1466 & Disease specific control groups. \\
\hline Meta-analysis (a-d) & 342 & 830 & 2113 & \\
\hline App+ & 61 & 62 & 424 & App data missing for 166 controls and 1 \\
\hline App- & 280 & & 1523 & \\
\hline $\begin{array}{l}\mathrm{p} \text { Value (App+: disease } v \\
\text { controls) }\end{array}$ & 0.12 & $\begin{array}{l}<0.0001 ; \text { OR } 0.29 \\
(\mathrm{Cl} 0.22-0.38)\end{array}$ & & $\begin{array}{l}\text { OR (CI) of App+ in UC relative to App+ in } \\
\text { control group. }\end{array}$ \\
\hline \multicolumn{5}{|c|}{ II: Appendicectomy v colorectal cancer: meta-analysis of two studies } \\
\hline Meta-analysis (c, d) & 113 & 530 & \multirow{4}{*}{\multicolumn{2}{|c|}{$\begin{array}{l}\text { High grade dysplasia not analysed because these data not available } \\
\text { in (c). } \\
\text { Prior appendicectomy data missing for } 1 \text { PSC-IBD case. } \\
\text { OR (CI) of colorectal cancer in UC patients with prior appendicectomy } \\
\text { relative to UC patients who have not undergone prior } \\
\text { appendicectomy. }\end{array}$}} \\
\hline App+ (CRC) & $26(1)$ & $28(3)$ & & \\
\hline App - (CRC) & $86(3)$ & $502(4)$ & & \\
\hline $\mathrm{p}$ Value (CRC $\vee$ App + ) & 1.0 & 0.004; OR 14.9 (Cl 3.2-70) & & \\
\hline
\end{tabular}

PSC, primary sclerosing cholangitis; IBD, inflammatory bowel disease; UC, ulcerative colitis; OR, odds ratio; Cl, confidence interval; App, appendicectomy; CRC, colorectal cancer.

consistent with the proposition that appendicectomy predisposes to colorectal cancer in UC or PSC-IBD but of course do not prove it because the disease groups, patient populations, and criteria used for disease ascertainment—although probably not too heterogeneous-were not the same. There are studies in the literature that have investigated appendicectomy and colorectal cancer in non-IBD populations. ${ }^{27-30}$ One of these, ${ }^{27}$ a retrospective case control study, reported a positive association. However, the follow up period in the only prospective study ${ }^{30}$ with $95 \%$ of its cohort under 40 years was not sufficiently long to allow critical assessment of the effect of appendicectomy on sporadic colorectal cancer.

Immune surveillance of the colon may be impaired with PSC or with appendicectomy. We hypothesised ${ }^{6}$ that lymphocytes within the appendix may be necessary for seeding the immune system of the gut with plasma cells. IgA (or $\operatorname{IgM})$ produced by these cells has an important role in excluding bacteria. With regard to UC, there is also a problem with immunoglobulin switching with a surfeit of IgG producing plasma cells in the lamina propria. ${ }^{31}{ }^{32}$ IgG causes inflammation by binding complement. If appendicectomy reduced IgA and IgG plasma cells in the colonic mucosa, then it could protect against severe colitis while promoting a milder but more extensive phenotype. PSC is also associated with an extensive mild colitis but the extent of colitis in PSCIBD, in sharp contrast with the colitis in UC, is not influenced by appendicectomy. This suggests that there is some other factor, due to or associated with the factor(s) that promotes PSC, which also promotes the characteristically mild but extensive colitic phenotype in PSC-IBD and the associated tendency to colorectal cancer. The pathogenesis of PSC is poorly understood but several mechanisms have been proposed. These include portal bacteraemia, toxic bile acid metabolites, toxic bacterial products, viral infection, ischaemia, and genetic and immunological factors. There is an association between MHC and PSC. ${ }^{33-35}$ The association with MHC class II DR3 and DR4 suggests a role for B lymphocytes and/or antigen presenting cells. ${ }^{36}$ Increased circulating B lymphocytes ${ }^{37}$ and hypergammaglobulinaemia ${ }^{38}$ are characteristic of PSC. Thus there may be a more global problem in PSC with impairment of gut and biliary B lymphocytes. We have recently reported that a CCR5 polymorphism is associated with PSC but not IBD. ${ }^{39}$ Thus impaired homing and aberrant immunoglobulin switching ${ }^{32}$ that results in a relative surfeit of IgG producing plasma cells could result in pathological binding of complement and so promoting a cellular immune response in colonic and biliary mucosa. The colonic disease may be milder in PSC-IBD because there are less IgA producing or IgG producing plasma cells but its extent would be increased because of diminished bacterial exclusion throughout the intestine.

In conclusion, in contradistinction to UC, appendicectomy does not significantly influence the prevalence of the PSC patient groups, or the extent of colitis in PSC-IBD, but as with UC, it does appear to delay their onset. The extensive milder colitis, which is characteristic of PSC-IBD, relates to other poorly understood factors. These factors are possibly the same as those enigmatic factors that determine the pathogenesis of PSC. Further prospective studies are required to characterise the influence of appendicectomy on the extent of colitis in IBD and on the associated dysplasia or colorectal cancer.

\section{ACKNOWLEDGEMENTS}

We are grateful to Dr J Fawcett (Princess Alexandra Liver Transplant Service), Professor N Martin (Population Health Unit, Queensland Institute of Medical Research), and Dr D Purdie (Population Health Unit, Queensland Institute of Medical Research) for their advice and encouragement. We also thank Pfizer (formerly Pharmacia Australia) for their ongoing support for the database, and Mrs D Templeton (Brisbane IBD Research Group) for her assistance.

\section{Authors' affiliations}

T H J Florin, Brisbane IBD Research Group, and University of Queensland Department of Medicine and Mater Health Services, South Brisbane, Queensland, Australia

N Pandeya, Brisbane IBD Research Group, and Population Health Unit, Queensland Institute of Medical Research, Queensland, Australia G L Radford-Smith, Brisbane IBD Research Group, and Department of Gastroenterology, Royal Brisbane Hospital, Brisbane, Australia

\section{REFERENCES}

1 Gilat T, Hacohen D, Lilos P, et al. Childhood factors in ulcerative colitis and Crohn's disease. An international cooperative study. Scand J Gastroenterol 1987;22:1009-24.

2 Wurzelmann J, Lyles C, Sandler R. Childhood infections and the risk of inflammatory bowel disease. Dig Dis Sci 1994;39:555-60.

3 Rutgeerts $\mathbf{P}, D^{\prime}$ Haens $G$, Hiele $M$, et al. Appendicectomy protects against ulcerative colitis. Gastroenterology 1994;106:1251-3. 
4 Gent A, Hellier M, Grace R, et al. Inflammatory bowel disease and domestic hygiene in infancy. Lancet 1994;343:766-7.

5 Smithson J, Radford-Smith G, Jewell D. Appendicectomy and tonsillectomy in patients with inflammatory bowel disease. J Clin Gastroenterol 1995:21:283-6.

6 Radford-Smith G, Edwards J, Purdie D, et al. Protective role of appendicectomy on onset and severity of ulcerative colitis and Crohn's disease. Gut 2002;51:808-13.

7 Naganuma M, Lizuka B, Torii A, et al. Appendicectomy protects against the development of ulcerative colitis and reduces its recurrence: results of a multicenter case-controlled study in Japan. Am J Gastroenterol $2001 ; 96: 1123-6$

8 Cosnes J, Carbonnel F, Beaugerie L, et al. Effects of appendicectomy on the course of ulcerative colitis. Gut 2002;51:803-7.

9 Ghirardi M, Nascimbeni R, Mariani P, et al. Course and natural history of idiopathic ulcerative proctitis in adults. Ann Ital Chir 2002;73:155-8.

10 Broomé U, Løfberg R, Lundquist K, et al. Subclinical timespan of inflammatory bowel disease in patients with primary sclerosing cholangitis. Dis Colon Rectum 1995:38:1301-5.

11 Lundquist K, Broomé U. Differences in colonic disease activity in patients with ulcerative colitis with and without primary sclerosing cholangitis. Dis Colon Rectum 1997;40:451-6.

12 Uchida N, Ezaki T, Fukuma $\mathrm{H}$, et al. Concomitant colitis associated with primary sclerosing cholangitis. J Gastroenterol 2003;38:482-7.

13 Fausa O, Schrumpf E, Elgio K. Relationship of inflammatory bowel disease and primary sclerosing cholangitis. Semin Liver Dis 1991;11:31-9.

14 Boberg K, Schrumpf E, Fausa O, et al. Hepatobiliary disease in ulcerative colitis. An analysis of 18 patients with hepatobiliary lesions classified as smallduct primary sclerosing cholangitis. Scand J Gastroenterol 1994;29:744-52

15 Sandborn W, Loftus E, Ahlquist D. Association of primary sclerosing cholangitis and colorectal cancer in patients with ulcerative colitis: is it true and does it matter? Gastroenterology 1998;115:236-7

16 Faubion W, Loftus E, Sandborn W, et al. Pediatric "PSC-IBD": a descriptive report of associated inflammatory bowel disease among pediatric patients with PSC. J Paediatr Gastroenterol Nutr 2001 ;33:296-300.

17 Shetty K, Rybicki L, Brzezinski A, et al. The risk for cancer or dysplasia in ulcerative colitis patients with primary sclerosing cholangitis. Am J Gastroenterol 1999:94:1643-9.

18 Lindberg B, Broome U, Persson B. Proximal colorectal dysplasia or cancer in ulcerative colitis. The impact of primary sclerosing cholangitis and sulfasalzine. Dis Colon Rectum 2001;44:77-85.

19 Vera A, Gunson B, Ussatoff V, et al. Colorectal cancer in patients with inflammatory bowel disease after liver transplantation for primary sclerosing cholangitis. Transplantation 2003;75:1983-8.

20 Lennard-Jones J. Classification of inflammatory bowel disease. Scand J Gastroenterol 1989;170(suppl):2-6.

21 Duffy D, Martin N, Matthews J. Appendicectomy in Australian twins. Am J Hum Genet 1990;47:590-2.

22 Abraham N, Selby W, Lazarus R, et al. Is smoking an indirect risk factor for the development of ulcerative colitis? An age- and sex-matched case-control study. J Gastroenterol Hepatol 2003;18:139-46.
23 Lindberg E, Tysk C, Andersson K, et al. Smoking and inflammatory bowel disease. A case-control study. Gut 1988;29:352-7

24 Calkins B. A meta-analysis of the role of smoking in inflammatory bowel disease. Dig Dis Sci 1989;34:1841-54.

25 Selby W, Griffin S, Abraham N, et al. Appendectomy protects against the development of ulcerative colitis but does not affect its course. Am J Gastroenterol 2002;97:2834-8.

26 Fraser A, Orchard T, Robinson E, et al. Long-term risk of malignancy after treatment of inflammatory bowel disease with azathioprine. Aliment Pharmacol Ther 2002;16:1225-32.

27 Fan Y, Zhang C. Appendectomy and cancer-an epidemiological evaluation (in Chinese). Zhonghua Zhong Liu Za Zhi 1986:8:212-14.

28 Friedman G, Fireman B. Appendectomy, appendicitis, and large bowe cancer. Cancer Res 1990;50:7549-51.

29 Mellemkjaer $L$, Johansen $C$, Linet $M$, et al. Cancer risk following appendectomy for acute appendicitis (Denmark). Cancer Causes Control 1998:9:183-7

30 Cope J, Askling J, Gridley G, et al. Appendectomy during childhood and adolescence and the subsequent risk of cancer in Sweden. Pediatrics 2003; 111:1343-50.

31 Brandtzaeg $\mathbf{P}$, Baklien K. Immunohistochemical studies of the immunoglobulin-producing cell systems of the human intestinal mucosa. Acta Histochem Suppl 1980;21:105-19.

32 Thoree V, Golby S, Boursier L, et al. Related $\lg A 1$ and $\lg G$ producing cells in blood and diseased mucosa in ulcerative colitis. Gut 2002;51:44-50.

33 Schrumpf E, Fausa $O$, Forre $O$, et al. HLA antigens and immunoregulatory $T$ cells in ulcerative colitis associated with hepatobiliary disease. Scand J Gastroenterol 1982;17:187-91.

34 Chapman R, Varghese Z, Gaul R, et al. Association of primary sclerosing cholangitis with HLA-B8. Gut 1983;24:38-41.

35 Donaldson P, Farrant J, Wilkinson M, et al. Dual association of HLA DR2 and DR3 with primary sclerosing cholangitis. Hepatology 1991;13:129-33.

36 Vuckovic S, Florin T, Khalil K, et al. CD40 and CD86 upregulation with divergent expression of CMRF44 on blood dendritic cells in patients with inflammatory bowel disease. Am J Gastroenterology 2001;96:2946-56

37 Lindor K, Wiesner R, Katzmann J, et al. Lymphocyte subsets in primary sclerosing cholangitis. Dig Dis Sci 1987;32:720-5.

38 Chapman R. Role of immune factors in the pathogenesis of primary sclerosing cholangitis. Semin Liver Dis 1991;11:1-4.

39 Eri $\mathbf{R}$, Jonsson J, Pandeya $\mathrm{N}$, et al. The CCR5 delta32 mutation is strongly associated with primary sclerosing cholangitis. Gastroenterology 2002; 122:A445.

40 van Erpecum K, Smits S, van de Meeberg $P$, et al. Risk of primary sclerosing cholangitis is associated with nonsmoking behavior. Gastroenterology 1996; 110:1503-6.

41 Mitchell S, Thyssen M, Orchard T, et al. Cigarette smoking, appendectomy, and tonsillectomy as risk factors for the development of primary sclerosing cholangitis: a case control study. Gut 2002;51:567-73.

\section{EDITOR'S QUIZ: GI SNAPSHOT}

\section{Answer}

From question on page 964

Small bowel barium through enema showed a $20 \mathrm{~cm}$ stenosis with parietal thickening located in a jejunal loop. Laparotomy showed an infiltrated jejunal loop, which was resected. The rest of the abdominal cavity examination was normal. Macroscopic findings showed jejunal stenosis due to ulcerations of the mucosae, which was thickened, with pseudomembranes.

Pathological findings showed jejunitis with typical intranuclear inclusions indicating a cytomegalovirus (CMV) infection. CMV jejunitis was confirmed by immunohistochemistry in jejunal tissue, which was strongly positive. CMV serological markers showed the presence of $\lg M$ and $\lg G$ anti-CMV antibodies. No immunosuppressive state was found: no corticosteroid intake; HIV antibodies, p24 antigenaemia, HTLV 1 and 2 antibodies, and Bence-Jones proteinuria were negative; protein immunoelectrophoresis, CD4 and CD8 counts, and thorax and abdominal computerised tomography scan did not show any abnormality. Gastrointestinal CMV infection usually occurs in non-immunocompetent patients and often presents as bloody diarrhoea. To our knowledge, this is the first case localised to the jejunum and presenting as a bowel obstruction in a immunocompetent patient. This case shows that CMV infection may present as a small bowel obstruction in healthy hosts. Therefore, CMV inclusions cells should be examined in mucosal biopsy specimens in patients with small bowel obstruction, to allow for the diagnosis. 